\title{
Nerve function impairment in leprosy: an epidemiological and clinical study - Part 2: Results of steroid treatment
}

\author{
W. H. VAN BRAKEL* \& I. B. KHAWAS \\ Green Pastures Hospital, PO Box 28, Pokhara, Nepal
}

Accepted for publication 28 November 1995

Summary This restrospective cohort study aimed to determine the progress of sensory and motor function during and after steroid treatment, and to identify any prognostic factors for the outcome of treatment.

The study used one hundred and sixty-eight leprosy patients registered at Green Pastures Hospital, Pokhara, West Nepal, who were treated with one of four different corticosteroid regimens for impairment of nerve function.

The function of the main peripheral nerve trunks affected in leprosy was assessed with a nylon filament to test touch thresholds (TST) and a manual voluntary muscle test (VMT) to quantify muscle strength. The TST and VMT scores at 3 months after initiation of steroid treatment served as the main outcome measure. The significance of potential prognostic factors was evaluated with logistic regression.

At 3 months, the sensory and motor function of the majority of patients with 'recent' impairment ( = less than 6 months duration) had improved significantly ( $p<0.01$, Wilcoxon matched pairs signed-ranks test). The likelihood of 'good' recovery (prognosis) for both sensibility and motor function was directly related to the severity of the nerve damage at the beginning of treatment.

Although nerve function improved in $30-84 \%$ (depending on the type of nerve) of patients, an active search for better methods of treatment and improved regimens is justified. The need for early assessment and treatment is stressed.

\section{Introduction}

The most important method of preventing disabilities in leprosy patients is the early detection and adequate treatment of neural impairment. ${ }^{1}$ The benefits of steroid treatment of leprosy reactions and leprous neuropathy have been recognized for several decades. $^{2}$ Its use appears to be safe as, fortunately very few serious side-effects have been reported thus far. ${ }^{3,4}$ To date there is no consensus about the regimen or type of

* Correspondence address: c/o INF, PO Box 5, Pokhara, Nepal 
corticosteroids that should be used. To our knowledge no randomized controlled trials have been conducted to determine an optimal regimen. No data have been published comparing nerve function at the beginning and completion of antileprosy treatment. The studies that have given details of the outcome of (anti-)neuritis treatment have mainly used motor function as a parameter for assessment. ${ }^{5,6}$ This is surprising since the value of sensibility testing using graded nylon monofilaments, especially for detecting mild (early?) nerve function impairment (NFI), has already been reported in 1977 by Naafs. ${ }^{7}$ The importance of sensibility testing was again stressed by Brandsma in $1981,{ }^{8}$ by Pearson, reporting on an international workshop on nerve damage, in $1982,{ }^{9}$ and recently by Palande \& Bowden. ${ }^{10}$

This lack of reference data prompted us to conduct the present study. It was carried out at Green Pastures Hospital (GPH), a 100-bed leprosy referral hospital in Pokhara, West Nepal, run by the International Nepal Fellowship. Good, standardized recordkeeping and nerve function assessment (NFA) protocols allowed retrospective analysis of a 4-year patient cohort (1988-92). The aims were: 1, to determine the progress of sensory and motor function during and after antineuritis treatment, analysing results with respect to the duration of impairment, type of nerve, different treatment regimens, the Ridley-Jopling classification of leprosy and extent of clinical disease; and 2, to identify any prognostic factors for the outcome of treatment.

\section{Methods}

CRITERIA FOR INCLUSION AND EXCLUSION OF PATIENTS

Between January 1988 and January 1992 all newly-registered patients with impaired nerve function, all treated patients who developed clinically detected neural impairment, and all patients who were ref erred to GPH for treatment of neuropathy were included in the study. Patients whose steroid treatment was started elsewhere more than one week before arrival at GPH were excluded.

\section{PATIENTS AND STUDY DESIGN}

A retrospective analysis was carried out of a 4-year-patient cohort (1988-92). Two hundred and eighty-seven patients had neural impairment and of these 168 were treated with corticosteroids, and are the subject of the present study. Since this was a retrospective analysis several of the patients admitted in GPH were lost to follow-up because they were referred elsewhere after discharge from the hospital. Nevertheless, all patients who were started on treatment were included in the analysis, whether or not they were lost to follow-up. Furthermore, we compared the 3-month results for patients who had no 6-month follow-up with the 3-month results of those who did, to examine whether any systematic differences existed. ${ }^{11}$ The 'lost to follow-up group' was not significantly different from the remaining patients in sex, age, improvement of overall TST and VMT scores at 3 months, or extent of clinical disease. Only the proportion of patients treated with dexamethason was higher in the 'lost to follow-up group'. We chose to use the 3-month results as the main end point for analysis, because the losses to follow-up were still within acceptable limits at that time $(12 \% \mathrm{vs}$ 
$39 \%$ at 6 months). In addition, most of the observed improvement in neural function occurred within the first 3 months.

\section{DIAGNOSIS AND CLASSIFICATION}

Methods of diagnosis and classification, using the Ridley-Jopling classification, as well as our 'body area classification system', laboratory examinations and histology have been described in detail in a previous paper. ${ }^{12}$ Briefly, the body area system is based on a count of the number of areas out of a total of 9 that show primary or secondary signs of leprosy (head, 4 extremities, front and back, both divided into left and right side). These may include skin lesions, enlarged nerves, clawing of fingers and other paralytic deformities, and ulcers. A patient with three or more affected body areas is referred to as having 'extensive disease' (multibacillary, MB). All others are classified as having 'limited disease' (paucibacillary, PB). The Ridley-Jopling classification was usually based on clinical criteria (including skin smears) as outlined by Jopling. ${ }^{13}$ In about $30 \%$ of the patients it was supported by a skin biopsy.

\section{DEFINITION OF NERVE FUNCTION IMPAIRMENT (NFI)}

NFI refers to impairment of function of large, peripheral nerve trunks. A patient was considered to have neurological impairment if there was a deterioration of more than 2 points in his voluntary muscle test (VMT) score, or 2 points or more in his touch sensibility test (TST) score compared to the previous result. Impairment of less than six months duration was classified as 'recent', if of longer duration, it was classified as 'old'. If no previous VMT and TST results were available, a patient was considered to have motor impairment if his VMT score was down by more than 2 points compared to the maximum score and, similarly, sensory impairment if his TST score was down by 2 points or more. In this case the patient's history was used to decide whether the impairment was 'recent' or 'old'.

\section{NERVE FUNCTION ASSESSMENT}

Nerve function was tested by one of two trained physiotechnicians at first examination, at every visit to the out-patient department, at annual examinations during and after termination of treatment, and 2-weekly for patients receiving treatment for a reaction or NFI.

\section{VOLUNTARY MUSCLE TEST (VMT)}

A full VMT was performed using the modified MRC scale as described by Brandsma. ${ }^{8}$ The VMT score consisted of the sum of individual muscle scores $(0-5 ; 0$, paralysed; 5 , normal strength). Details of the muscles tested can be found in the Appendix.

TOUCH SENSIBILITY TEST (TST)

Touch sensibility thresholds of skin areas on the hand supplied by the ulnar and median 
nerves were tested using a nylon monofilament giving a force of approximately $10 \mathrm{~g}$ when pressed until it bent. The result was recorded as 'felt' or 'not felt' for each of the sites mentioned below. If the patient sometimes felt the touch and sometimes not, the result was recorded as 'partial'. When necessary the test was repeated until the examiner was confident about the patient's response. Sensibility on the sole of the foot was tested in a similar way using a thicker monofilament, giving a force of about $75 \mathrm{~g}$. The TST score consisted of the sum of scores given for individual sites (2, monofilament felt; 1 , doubtful; 0, monofilament not felt). The test sites are given in the Appendix.

\section{TREATMENT}

Only patients with recent NFI (see above), and who had no other concurrent severe illness, such as untreated tuberculosis, were considered eligible for systemic steroid treatment. The following corticosteroid regimens were used consecutively during the study period:

Dexamethasone 6 milligrams (mg) daily single dose (od) initially, tapering approximately 1 tablet $(0.5 \mathrm{mg})$ every 2 weeks, depending on the progress of the patient, thus giving a duration of treatment of about 6 months $(N=49)$.

Prednisolone $30 \mathrm{mg}$ twice daily (bd) initially, tapering as under ' 1 ' ( 1 tablet $=5 \mathrm{mg}$ ), $(N=45)$.

Prednisolone $60 \mathrm{mg}$ once daily (od) initially, tapering as under '1' $(N=40)$.

Prednisolone $40 \mathrm{mg}$ od, tapering $5 \mathrm{mg}$ every 2 weeks, depending on the progress of the patient, duration about 4 months $(N=34)$.

\section{STATISTICAL CONSIDERATIONS AND METHODS}

We chose to analyse the results using patients rather than nerves as denominators, because patients were being treated and not individual nerves. Most patients had more than one nerve affected and thus the nerves of one patient were not (statistically) independent of each other. All calculations below are therefore based on one nerve per patient. For example, if a patient had both ulnar and median impairment, he would appear once in the ulnar nerve analysis and again in the median nerve-only analysis. The same patient was, therefore, never counted twice in any given numerator or denominator. If a patient had both left and right nerves of one type affected, only the data of the most severely and most recently affected nerve were analysed.

To examine trends the VMT and TST scores were categorized into 'good', 'moderate', 'bad' and 'absent' as shown in Table 1. Similar classifications for motor function were used by Srinivasan and Kiran. ${ }^{5,14}$ The cutoff scores for the categories were arbitrarily chosen. The change in VMT and TST score observed at 3 months after the beginning of treatment was calculated. 'Improved' was defined as a difference in TST or VMT score of more than one point on the scale; a difference of between -1 and 1 was called 'same', while a deterioration of more than -1 was called 'worse'. We used non-parametric methods, because the measurement scales were ordinal (no equal intervals between points on the scale) and because the scores were often not normally distributed. The median value of the scores at each time point was computed and the 
Table 1. Nerve function classification for each of the nerves in the study

\begin{tabular}{|c|c|c|c|c|c|c|}
\hline $\begin{array}{l}\text { Sensory } \\
\text { categories }\end{array}$ & $\begin{array}{l}\text { Ulnar } \\
\left(3 \text { sites* }^{*}\right)\end{array}$ & $\begin{array}{l}\text { Median } \\
\text { (4 sites) }\end{array}$ & $\begin{array}{l}\text { Post. tibial } \\
\text { (10 sites) }\end{array}$ & Radial & $\begin{array}{c}\text { Lateral } \\
\text { popliteal }\end{array}$ & Facial† \\
\hline Anaesthetic & $0-2$ & $0-2$ & $0-2$ & & & \\
\hline $\mathrm{Bad}$ & 3 & $3-4$ & $3-10$ & & & \\
\hline Moderate & 4 & $5-6$ & $11-17$ & & & \\
\hline Good & $5-6$ & $7-8$ & $18-20$ & & & \\
\hline $\begin{array}{l}\text { Motor } \\
\text { categories }\end{array}$ & (2 muscles) & ( 2 muscles) & & (2 muscles) & ( 2 muscles) & (1 muscle) \\
\hline Paralysed & $0-1$ & $0-1$ & & $0-1$ & $0-1$ & $0-1$ \\
\hline $\mathrm{Bad}$ & $2-4$ & $2-4$ & & $2-4$ & $2-4$ & 2 \\
\hline Moderate & $5-7$ & $5-7$ & & $5-7$ & $5-7$ & 3 \\
\hline Good & $8-10$ & $8-10$ & & $8-10$ & $8-10$ & $4-5$ \\
\hline
\end{tabular}

* maximum score per site: 2 . $†$ The facial nerve data in Table 4 are presented uncoded, because only 1 muscle was tested on a $0-5$ scale.

Wilcoxon matched-pairs signed-ranks test ${ }^{15}$ was used to compare paired data. The Mann-Whitney U test ${ }^{15}$ and Kruskal-Wallis one-way analysis of variance ${ }^{16}$ were used for independent group comparisons. The difference between proportions was tested using the Standard Normal Deviate (SND) for unpaired sample proportions. ${ }^{15}$ The significance of possible prognostic factors was evaluated with logistic regression, ${ }^{17}$ using the proportion of patients with a 'good' result at 3 months as outcome measure. A $p$-value of less than $5 \%$ was used as the level of statistical significance. Where appropriate the $95 \%$ confidence interval is given. Analysis was done, using Epi Info software, version $5 \cdot 01^{18}$ and SPSS for Windows, version $6 \cdot 0$.

Table 2. Improvement* of sensory and motor scores in 150 patients divided in 'nerve groups', 3 months after initiation of steroid treatment

\begin{tabular}{lccc}
\hline & $\begin{array}{c}\text { Improved* } \\
(95 \% \mathrm{CI})\end{array}$ & Same $(\%)$ & Worse (\%) \\
\hline UST $\dagger$ & $60(48-71)$ & $34(23-46)$ & $6(0 \cdot 3-12)$ \\
Median $(\mathrm{n}=42)$ & $84(73-95)$ & $16(5 \cdot 2-27)$ & \\
Posterior tibial $(\mathrm{n}=57)$ & $72(56-78)$ & $14(5 \cdot 3-22)$ & $14(5 \cdot 3-22)$ \\
VMT $\ddagger$ & & & \\
\hline Facial $(\mathrm{n}=48)$ & & & \\
Ulnar $(\mathrm{n}=85)$ & $29(16-42)$ & $71(58-84)$ & $4(0-7 \cdot 5)$ \\
Median (n=21) & $47(36-57)$ & $49(39-60)$ & $5(0-14)$ \\
Lateral popliteal $(\mathrm{n}=34)$ & $76(58-94)$ & $19(2 \cdot 3-36)$ & $3(0-8 \cdot 6)$ \\
& $73(59-88)$ & $24(9 \cdot 3-38)$ & \\
\hline
\end{tabular}

*proportion of patients improved with $95 \%$ confidence interval, 'Improved' = increase inVMT/TST score of $>1$ point, 'same' = change in score between -1 and 1 , and 'worse' = deterioration of more than 1 point on the VMT/TST scale. †touch sensibility test (using 1 nylon monofilament), łvoluntary muscle test. 


\section{Results}

PATIENTS

A total of 168 patients with sensory and/or motor impairment were included in the analysis. They were classified as follows: BT 55, BB 5, BL 67, LL 34, pure neuritic (PN) 7. The mean age was 40 years (range 11-70); 130/168 were male. One hundred and forty-seven patients received or had been released from WHO multidrug therapy (MDT), 20 were on dapsone monotherapy and 1 patient on clofazimine monotherapy. Of these 168 patients, 104 had sensory and 125 motor impairment at the beginning of treatment (the numbers do not add up to 168 , because many patients had both types of impairment).

\section{SENSORY NERVES}

Table 2 shows for each nerve the proportion of patients who improved, stayed the same or got worse. Eighteen patients had been lost to follow-up, therefore only data on 150 patients are shown in Table 2. A significantly larger proportion of patients with median nerve lesions improved compared to those with impairment of the ulnar nerve ( $p=0 \cdot 008$, SND test). Results of treatment of the different sensory nerves are shown in Table 3. The sensory scores of the majority of patients with lesions of the ulnar, median and posterior tibial nerves improved until 3 months after the beginning of steroid treatment $(p<0 \cdot 001$, Wilcoxon's test).

\section{MOTOR NERVES}

The progress of the motor scores shown in Table 4 was significant for each nerve group. Improvement in the facial and ulnar nerves was remarkably less than in the median and lateral popliteal nerves (Table $2, p=0 \cdot 017$, SND test). The motor function of the ulnar and lateral popliteal nerves stopped improving after 3 months, while that of the facial and median nerves continued to improve up to 6 months after starting steroid treatment. The possibility of improvement beyond the period of the study cannot be excluded.

\section{TIME TRENDS}

Figures 1 and 2 show the trend of sensory and motor nerve scores over time. Only data of patients who had impairment before the start of steroid treatment are shown (104 patients with sensory deficits, and 125 with motor lesions). The rate of improvement in both sensibility and motor function slowed down after 3 months. In both, the only changes after 3 months were between the 'moderate' and 'good' group, while the proportions 'bad' and 'anaesthetic/paralysed' remained the same. Figures 3 and 4 illustrate the proportion of patients whose sensory and motor nerves either improved, stayed the same or deteriorated during a period of 6 months after initiation of steroid treatment. The most rapid improvement occurred during the first month of steroid treatment. This was most pronounced in patients with sensory impairment. Most of the improvement in the first month occurred already during the first 2 weeks (35/37 patients who improved, data not shown). The proportion of patients whose sensory function had improved at 3 months was larger than the proportion with motor improvement (67 vs $50 \%$ ). Nevertheless, the proportion with good function at 3 months was not very 
Table 3. Change in sensory scores over time (bef ore treatment, at 1, 3 and 6 months) in leprosy patients treated for neural impairment with corticosteroids.

\begin{tabular}{|c|c|c|c|c|c|c|c|c|}
\hline \multirow[b]{2}{*}{ Ulnar } & \multicolumn{8}{|c|}{ Time interval from the start of steroid treatment } \\
\hline & $\begin{array}{c}\text { start } \\
(n=168)\end{array}$ & $\%$ & $\begin{array}{c}1 \mathrm{~m}^{*} \\
(n=160)\end{array}$ & $\%$ & $\begin{array}{c}3 \mathrm{~m} \\
(n=150)\end{array}$ & $\%$ & $\begin{array}{c}6 \mathrm{~m} \\
(n=110)\end{array}$ & $\%$ \\
\hline Anaesthetic & $61 \dagger$ & 86 & 48 & 70 & 28 & 42 & 17 & 39 \\
\hline Bad & 1 & 1 & & & 1 & 2 & & \\
\hline Moderate & 9 & 13 & 9 & 13 & 10 & 15 & 4 & 9 \\
\hline Good & & & 12 & 17 & 27 & 41 & 23 & 52 \\
\hline Total & 71 & 100 & 69 & 100 & 66 & 100 & 44 & 100 \\
\hline median score $\ddagger$ & 0 & & 0 & & 4 & & 6 & \\
\hline Median & & & & & & & & \\
\hline Anaesthetic & 22 & 48 & 18 & 39 & 5 & 12 & 3 & 11 \\
\hline Bad & 14 & 30 & 6 & 13 & 8 & 19 & 3 & 11 \\
\hline Moderate & 10 & 22 & 11 & 24 & 8 & 19 & 7 & 25 \\
\hline Good & & & 11 & 24 & 21 & 50 & 15 & 53 \\
\hline Total & 46 & 100 & 46 & 100 & 42 & 100 & 28 & 100 \\
\hline median score & 4 & & 4 & & 7 & & 8 & \\
\hline Posterior tibial & & & & & & & & \\
\hline Anaesthetic & 23 & 36 & 21 & 35 & 12 & 21 & 7 & 19 \\
\hline $\mathrm{Bad}$ & 18 & 29 & 19 & 32 & 14 & 25 & 7 & 19 \\
\hline Moderate & 22 & 35 & 11 & 18 & 11 & 19 & 11 & 30 \\
\hline Good & & & 9 & 15 & 20 & 35 & 12 & 32 \\
\hline Total & 63 & 100 & 60 & 100 & 57 & 100 & 37 & 100 \\
\hline median score & 7 & & 8 & & 14 & & 14 & \\
\hline
\end{tabular}

$*$ month(s), $\dagger$ the number in each cell refers to the number of patients in that category; patients with a normal (good) sensory function at the start of treatment have been omitted. $\ddagger$ median value of the sensory test scores of the nerves with functional impairment at each point in time.

different (42 vs 36\%), because initial impairment was much more severe in the sensory group. After the third month there was very little further improvement.

\section{PROGNOSTIC FACTORS}

No significant influence on the treatment outcome could be demonstrated for age, antileprosy treatment, bacteriological index, number of lesions or number of body areas, or reported time-lapse between onset and treatment of the nerve damage. Male sex seemed to significantly increase the likelihood of good motor recovery (adjusted odds ratio $7 \cdot 3(2 \cdot 0-26), p=0 \cdot 017)$. The level of impairment at the onset of steroid treatment has a significant influence on the outcome as is shown in Table 5 . Only $35 \%$ of patients with complete anaesthesia and $11 \%$ with complete motor paralysis improved to good function at 3 months, compared to $67 \%$ and $55 \%$ for patients with moderate impairment. The difference is significant $(p<0 \cdot 01$, SND test).

\section{Discussion}

The most important outcome of treatment for the individual leprosy patient is whether 


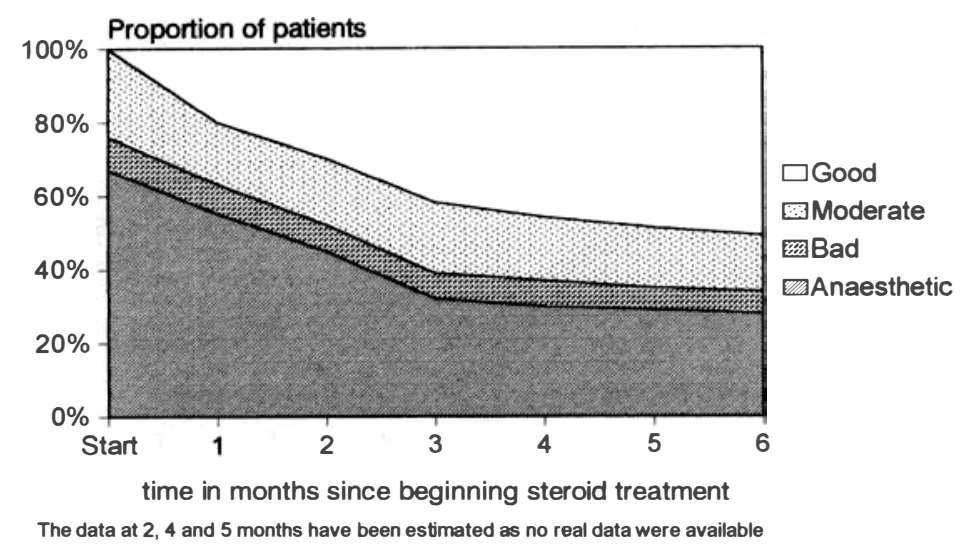

Figure 1. Proportion of patients with different levels of sensory impairment during steroid treatment $(n=104$ at the beginning of treatment).

he will have residual disabilities, handicaps and/or deformities. Most disabilities and deformities result from impairment of peripheral nerve function (NFI). Thus, early detection and treatment of such impairment are very important.

Due to the retrospective nature of this study, a considerable proportion of patients $(39 \%)$ had been lost to follow-up at 6 months after initiation of treatment. This could have seriously biased our results, if those patients discharged early had made a better recovery than the remaining ones. Comparing the 3-month results of patients who had been discharged early with the 3-month results of those reviewed at 6 months, showed no significant differences between the two groups. However, to be on the safe side, we used the results at 3 months as our main assessment of treatment.

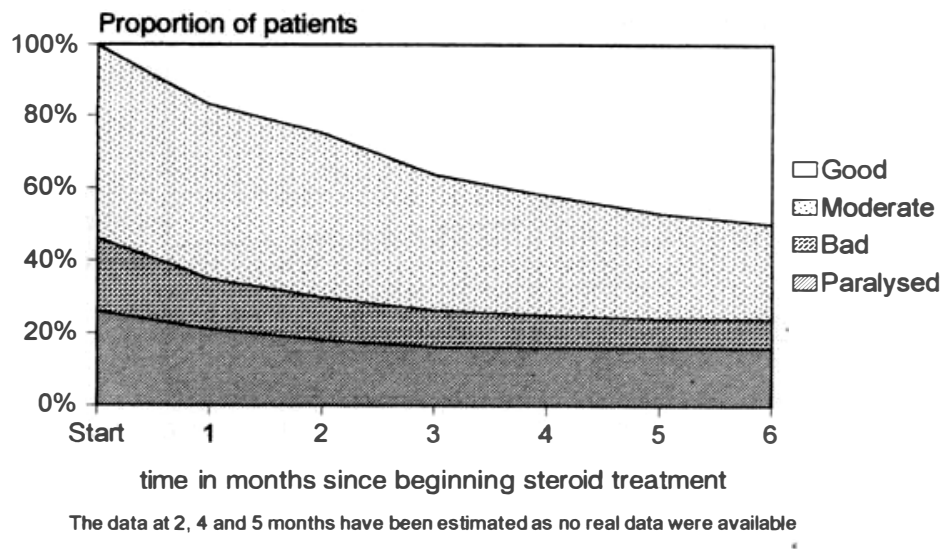

Figure 2. Proportion of patients with different levels of motor impairment during steroid treatment $(n=125$ at the beginning of treatment). 


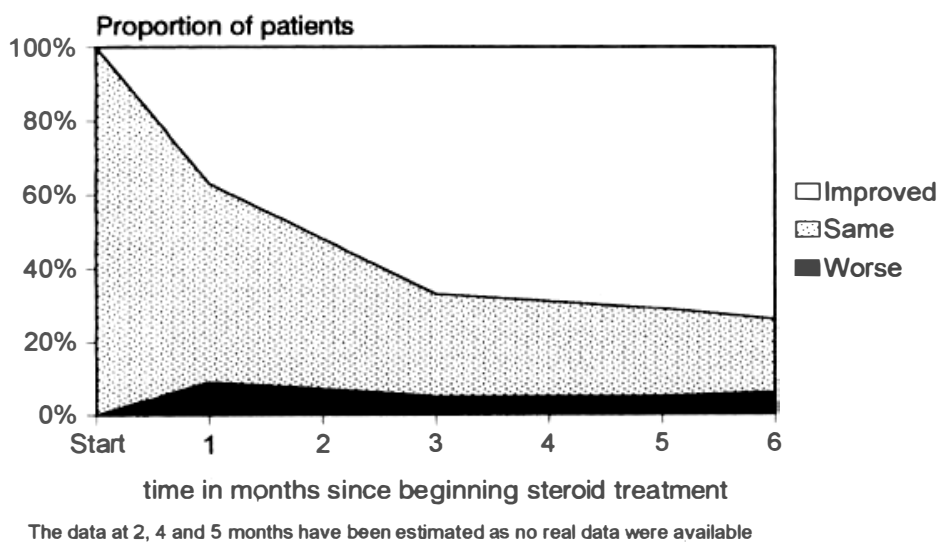

Figure 3. Progress of sensory function in leprosy patients during steroid treatment $(n=104$ at the beginning of treatment).

\section{CRUDENESS OF NERVE FUNCTION ASSESSMENT}

The voluntary muscle test (VMT) used in our hospital is the one recommended by Brandsma. ${ }^{8}$ Although this test is widely used, it may not be sensitive enough to pick up mild impairment. ${ }^{7}$

Our standardized touch sensibility test (TST) was very crude. We used a monofilament of approximately $10 \mathrm{~g}$ force for the hand and one of $75 \mathrm{~g}$ force for the foot sole. Recently, normal threshold forces in healthy Nepali subjects were found to be $70-$ $200 \mathrm{mg}$ for the hand and $2 \mathrm{~g}$ for the sole of the foot. ${ }^{19}$ This means that our test consistently underestimated the extent of sensory impairment, but that, if impairment was detected, the sensibility of that particular patient was definitely impaired. In other words, our sensibility test had low sensitivity, but high specificity. The low sensitivity should not affect serial comparisons, as it was consistent throughout the study period.

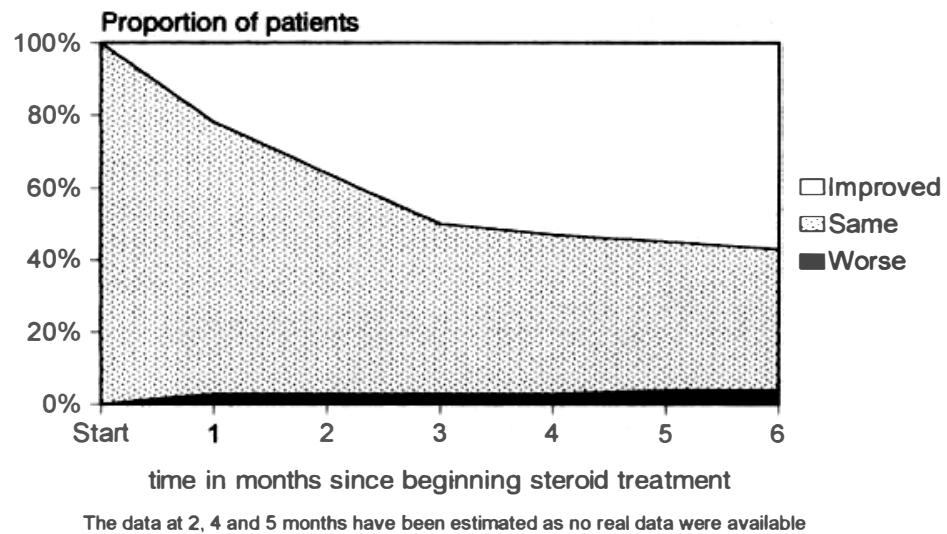

Figure 4. Progress of motor function in leprosy patients during steroid treatment $(n=125$ at the beginning of treatment). 
Table 4. Change in motor function scores over time (before treatment, at 1, 3 and 6 months) in leprosy patients treated for neural impairment with corticosteroids.

\begin{tabular}{|c|c|c|c|c|c|c|c|c|}
\hline \multirow[b]{2}{*}{ Ulnar } & \multicolumn{8}{|c|}{ Time interval from the start of steroid treatment } \\
\hline & $\begin{array}{c}\text { start } \\
(n=168)\end{array}$ & $\%$ & $\begin{array}{c}\operatorname{lm}^{*} \\
(n=160)\end{array}$ & $\%$ & $\begin{array}{c}3 \mathrm{~m} \\
(n=150)\end{array}$ & $\%$ & $\begin{array}{c}6 \mathrm{~m} \\
(n=110)\end{array}$ & $\%$ \\
\hline Paralysed & $19 \dagger$ & 20 & 17 & 19 & 13 & 15 & 11 & 18 \\
\hline $\mathrm{Bad}$ & 23 & 24 & 13 & 14 & 8 & 9 & 3 & 5 \\
\hline Moderate & 54 & 56 & 46 & 50 & 33 & 39 & 18 & 30 \\
\hline Good & & & 16 & 17 & 31 & 37 & 28 & 47 \\
\hline Total & 96 & 100 & 92 & 100 & 85 & 100 & 60 & 100 \\
\hline median score $\ddagger$ & 5 & & 6 & & 7 & & 7 & \\
\hline \multicolumn{9}{|l|}{ Median } \\
\hline Paralysed & 5 & 20 & 5 & 39 & 4 & 19 & 3 & 20 \\
\hline $\mathrm{Bad}$ & 4 & 15 & 3 & 12 & 1 & 5 & 3 & 20 \\
\hline Moderate & 17 & 65 & 11 & 44 & 1 & 5 & 1 & 7 \\
\hline Good & & & 6 & 24 & 15 & 71 & 8 & 53 \\
\hline Total & 26 & 100 & 25 & 100 & 21 & 100 & 15 & 100 \\
\hline median score & 6 & & 6 & & 8 & & 9 & \\
\hline \multicolumn{9}{|l|}{ Lateral popliteal } \\
\hline Paralysed & 8 & 21 & 4 & 11 & 2 & 6 & & \\
\hline $\mathrm{Bad}$ & 4 & 10 & 4 & 11 & 3 & 9 & 3 & 13 \\
\hline Moderate & 27 & 69 & 19 & 51 & 12 & 35 & 5 & 22 \\
\hline Good & & & 10 & 27 & 17 & 50 & 15 & 65 \\
\hline Total & 39 & 100 & 37 & 100 & 34 & 100 & 23 & 100 \\
\hline median score & 5 & & 7 & & 8 & & 8 & \\
\hline \multicolumn{9}{|l|}{ Facial } \\
\hline 0 & 19 & 34 & 15 & 28 & 5 & 10 & & \\
\hline 1 & 3 & 5 & & & 7 & 15 & 3 & 9 \\
\hline 2 & 7 & 13 & 12 & 22 & 6 & 12 & 7 & 22 \\
\hline 3 & 27 & 48 & 21 & 39 & 16 & 33 & 6 & 19 \\
\hline 4 & & & 6 & 11 & 7 & 15 & 8 & 25 \\
\hline 5 & & & & & 7 & 15 & 8 & 25 \\
\hline Total & 56 & 100 & 54 & 100 & 48 & 100 & 32 & 100 \\
\hline median score & 2 & & 3 & & 3 & & 4 & \\
\hline
\end{tabular}

$*$ month(s), $\dagger$ the number in each cell refers to the number of patients in that category; patients with a normal motor function in a given nerve have been omitted, $\ddagger$ median value of the VMT scores at each point in time.

\section{TIMING OF TREATMENT}

It is generally believed that corticosteroid treatment is effective in cases with neural impairment 'of recent onset.' Usually an arbitrary time limit of 6 months duration is chosen as a definition of 'recent onset'. 3,5 Common sense would argue that NFI treated 'early' should respond better to treatment than when treated 'late', but very little evidence for this could be found in the literature. Srinivasan et al. reported that in a sample of 25 patients with 'quiet nerve paralysis' $83 \%$ of nerves with paralysis of $1-13$ weeks duration recovered 'satisfactorily' (=VMT score of $3+$ or more on the MRC scale). Only $53 \%$ of nerves with paralysis of 'longer duration' improved satisfactorily. ${ }^{14}$ Job has shown that, particularly in lepromatous patients, peripheral nerves may already show evidence of advanced neuropathy bef ore they are 'clinically affected' ${ }^{\prime 20}$. McLeod et al., 
Table 5. Association between the level of impairment at the onset of treatment and after 3 months in patients with sensory and motor deficits.

Start*

Sensibility at 3 months

\begin{tabular}{|c|c|c|c|c|c|c|c|c|}
\hline & & Absent & $\mathrm{Bad}$ & Moderate & Good & $\% \dagger$ & Lost $\ddagger$ & Total \\
\hline Absent & & 29 & 3 & 9 & 22 & 35 & 7 & 70 \\
\hline Bad & & & 3 & 4 & 2 & 22 & & 9 \\
\hline \multirow[t]{3}{*}{ Moderate } & & 2 & 1 & 5 & 16 & 67 & 1 & 25 \\
\hline & Total & 31 & 7 & 18 & 40 & 42 & & 104 \\
\hline & & \multicolumn{7}{|c|}{ Motor function at 3 months } \\
\hline Absent & & 12 & 5 & 8 & 3 & 11 & 4 & 32 \\
\hline Bad & & 5 & 4 & 9 & 4 & 18 & 3 & 25 \\
\hline Moderate & & 1 & 2 & 24 & 33 & 55 & 8 & 68 \\
\hline & Total & 18 & 11 & 41 & 40 & 36 & & 125 \\
\hline
\end{tabular}

* Score category at the start of steroid treatment (See Table 1), † proportion of nerves scoring 'good' after 3 months among the total number in the row category (start of treatment), $\ddagger$ the number of patients in each category that was lost to follow-up at 3 months.

using nerve conduction studies, found signs of impairment of function in over half of 'clinically unaffected' nerves. ${ }^{21}$ This suggests that it may be possible to detect impairment earlier if more sensitive instruments were used. Studies are needed to investigate whether nerve lesions detected early respond better to treatment than those detected with current high threshold stimuli.

In the current study, there was a weak association between the reported duration of NFI and the results of treatment for patients with sensory impairment, but this association was no longer apparent after adjusting for age in multivariate analysis. The expected association may have been lacking because the information about duration of impairment was often based on the patient's history, which is not always very accurate concerning time related information.

\section{INDIVIDUAL NERVES}

A striking difference was observed in the response of the ulnar and median nerves. After 3 months $84 \%$ of patients with sensory and $76 \%$ of those with motor impairment of the median nerve had improved, whilst only $60 \%$ and $47 \%$, respectively, of patients with ulnar nerve lesions showed improvement. The difference for the sensory nerves can be (partly) explained by the much higher proportion of patients in the ulnar group with complete anaesthesia at the start of treatment (Table 3). The motor difference cannot be readily explained in this way. The fact that the ulnar motor function recovered less than that of other motor nerves averaged together, was described by Srinivasan et al. ${ }^{14}$ Improvement of a larger proportion of affected median motor nerves compared to ulnar motor nerves was also described by Touw et al., ${ }^{6}$ Kiran et $a l .{ }^{5}$ and Becx \& Berhe. ${ }^{3}$ The latter study reported on 161 patients treated with prednisolone in the field. Nerve function was assessed directly after stopping steroids, using a 3-point-scale 'field VMT' and the 'ballpen test' as sensory test. They found little difference between the different sensory nerves in the 
proportion that improved. Eighty-eight percent of patients showed 'partial or total recovery' of nerve function. ${ }^{3}$ A possible explanation for this much higher proportion of improved patients is that these patients received steroid treatment in 'the field' and that, therefore, they may on average have been treated earlier than our patients. In a recent study in Hyderabad, India, Lockwood et al. found no improvement of neurological impairment in $7 / 24(29 \%)$ of patients with neuritis who were treated with (low dose) prednisolone. ${ }^{22}$

Kiran et al, report $71 \%$ 'good' recovery (no lid gap on gentle closure) in 28 patients with lagophthalmos treated with a low dose steroid regimen (initially $25-30 \mathrm{mg}$ ) for 5-6 months. ${ }^{23}$ This figure is similar to ours, if the same criteria for 'good' recovery are applied (69\%, data not shown). None of the facial nerves deteriorated during treatment (Table 2). Becx-Bleumink found that $84 \%$ of lateral popliteal nerves showed improved motor function after treatment, ${ }^{3}$ compared to $73 \%$ among our patients.

\section{'FUNCTIONAL' NERVE SCORES}

To classify impairments into categories that may have some functional meaning, we classified the score before and after treatment into the groups 'absent', 'bad', 'moderate' and 'good', as described above. Our data show that the likelihood of 'good' recovery of both sensibility and motor function was directly related to the severity of the nerve damage at the beginning of treatment (Table 5). This confirms a similar observation by Srinivasan et al. for motor nerve function. ${ }^{5}$ It is interesting that there was no linear relationship between the extent of neural impairment and ability to recover, i.e. nerves that were clinically completely paralysed were still able to recover, although most of them did not regain full or 'good' function.

\section{TIME TRENDS}

The time trends showed that most of the recovery takes place in the first 3 months after initiation of steroid therapy (Figures 3 and 4). It was interesting that 35/64 patients $(55 \%)$ whose sensory function had improved by 3 months had already improved during the first 2 weeks of treatment. A similar rapid improvement following initiation of steroid therapy was described by Naafs \& Dagne. ${ }^{7}$ They observed improvement in motor nerve conduction in the first few days of treatment. This they attributed to reduction of the intraneural oedema as a result of the anti-inflammatory effect of steroids. To what extent the further improvement is due to remyelination, regeneration of nerve fibres or both, is, to our knowledge, unknown. The proportion of patients with improvement of sensory and motor function increased very little after 3 months. Improvement in the group of patients with severe neural impairment (bad or complete anaesthesia/paralysis) occurred only during the first 3 months. This 'levelling off' of improvement after 3-6 months was also described by Naafs et al. ${ }^{7,24}$ and TouwLangendijk et al. ${ }^{6}$

PROGNOSTIC FACTORS

The level of impairment at the beginning of steroid treatment had a significant 
independent effect on the outcome even after adjusting for age, sex, steroid regimen and classification. The use of more sensitive nerve assessment instruments, and perhaps testing of more modalities of neural function, should lead to detection of impairment at an earlier stage and will perhaps enable us to identify other prognostic factors. The use of sensitive tests of sensibility has made predictions of prognosis possible in the treatment of nerve injury and chronic compression neuropathy. ${ }^{25}$

Despite some improvement of nerve function in the majority of patients, we are not satisfied with the results. Several patients deteriorated during treatment in hospital. A larger proportion (32-47\%) showed no functional improvement at all, despite rigorous therapy for 'recent' impairment. Recent data from Malawi showed that even in a well-conducted field programme, $26.2 \%$ of patients developed new impairments or worsening of existing impairments during MDT. ${ }^{26}$ This led the authors to state that 'the present steroid treatment, even if instituted quickly, is unsatisfactory'. An active search for better methods of treatment and improved regimens is therefore justified.

\section{RECOMMENDATIONS}

Further research is needed to clarify the pathogenesis of neuropathy in the different forms of leprosy. Improved understanding should lead to improved treatment.

Controlled, randomized treatment trials of new anti-inflammatory or immunemodulating drugs and/or different steroid regimens are needed to improve therapy of neuropathy.

Early detection of nerve function impairment needs to be improved. Available techniques, like the Semmes-Weinstein monofilaments, should be made widely available and should be taught to all health workers caring for leprosy patients.

\section{Acknowledgments}

We are grateful to Professor F. G. I. Jennekens, Dr Y. van der Graaf and an anonymous referee for helpful comments during the preparation of this manuscript. We are indebted to the staff of the Physiotherapy Department at Green Pastures Hospital who spend much of their time performing detailed nerve function assessments, without which this study would not have been possible. The work at Green Pastures Hospital is dedicated to the service and glory of God.

\section{References}

${ }^{1}$ Watson JM. Essential action to minimise disability in leprosy patients. The Leprosy Mission International, 1988.

2 Pearson JMH. The use of corticosteroids in leprosy. Lepr Rev 1981; 52: 293-8.

3 Becx-Bleumink M, Berhe D. Occurrence of reactions, their diagnosis and management in leprosy patients treated with multidrug therapy; experience in the Leprosy Control Program of the All Af rica Leprosy and Rehabilitation Training Centre (ALERT) in Ethiopia. Int J Lepr 1992; 60: 173-84. 
${ }^{4}$ Becx-Bleumink M, Berhe D, 'T Mannetje W. The management of nerve damage in the leprosy control services. Lepr Rev 1990; 61: 1-11.

${ }^{5}$ Kiran KU, Stanley JNA. Pearson JMH. The outpatient treatment of nerve damage in patients with borderline leprosy using a semi-standardized steroid regimen. Le pr Rev 1985; 56: 127-34.

6 Touw-Langendijk EMJ, Brandsma JW, Andersen JG. Treatment of ulnar and median nerve function loss in borderline leprosy. Lepr Rev 1984; 55: 41-6.

${ }^{7}$ Naafs B, Dagne T. Sensory testing: a sensitive method in the follow-up of nerve involvement. Int J Lepr 1977; 45: 364-8.

8 Brandsma W. Basic Nerve function assessment in leprosy patients. Lepr Rev 1981; 52: 161-70.

9 Pearson JMH. The evaluation of nerve damage in leprosy. Lepr Rev 1982; 53: 119-30.

10 Palande DD, Bowden REM. Early detection of damage to nerves in leprosy. Lepr Rev 1992; 63: 60-72.

${ }^{11}$ Pocock SJ. Clinical Trials. A practical approach. John Wiley \& Sons (Publ), Chichester, 1988, pp 182.

12 van Brakel WH, de Soldenhoff R, McDougall AC. The allocation of leprosy patients into paucibacillary and multibacillary groups for multidrug therapy, taking into account the number of body areas affected by skin, or skin and nerve lesions. Lepr Rev 1992; 63: 231-45.

13 Jopling WH, McDougall AC. Handbook of Leprosy. 4th Edition. Heinemann Medical books Ltd, Oxf ord, 198.

14 Srinivasan H, Rao KS, Shanmugam N. Steroid therapy in recent 'quiet nerve paralysis' in leprosy. Lepr Ind 1982; 54: 412-9.

15 Armitage P, Berry G. Statistical Methods in Medical Research. 2nd ed. Oxford: Blackwell Scientific Publications, 1987; 121-4.

16 Kirkwood BR. Essentials of medical statistics. Blackwell Scientific Publications, Oxf ord, 1988.

17 Clayton D, Hills M. Statistical models in epidemiology. Oxford University Press, Oxford, 1993; p. 229.

18 Dean AG, Dean JA, Dicker RC. Epi Info, Version 5: a word processing, database, and statistics program for epidemiology on microcomputers. USD, Inc., Stone Mountain, Georgia, 1990.

19 Kets M, van Leerdam M, van Brakel WH, Khawas IB, Gurung KS. Reference values touch sensibility thresholds in healthy Nepalese volunteers. Lepr Rev 1996; 67: 28-38.

20 Job CK. Mycobacterium leprae in nerve lesions in lepromatous leprosy. Arch Path 1970; 89: $195--207$.

21 McLeod JG, Hargrave JC, Walsh JC, Booth GC, Gye RS, Barron A. Nerve conduction studies in leprosy. Int J Lepr 1975; 43: 21-31.

${ }^{22}$ Lockwood DNJ, Vinayakumar S, Stanley JNA, McAdam KPWL, Colston MJ. Clinical features and outcome of reversal (type 1) reactions in Hyderabad, India. Int J Lepr 1993; 61: 8-15.

${ }^{23}$ Kiran KU, Hogeweg M, Suneetha S. Treatment of recent facial nerve damage with lagophthalmos, using a semistandardized steroid regimen. Lepr Rev 1991; 62: 150-4.

${ }^{24}$ Naafs B, Pearson JMH, Baar AJM. A follow-up study of nerve lesions in leprosy during and after reaction using motor nerve conduction velocity. Int J Lepr 1976; 44: 188-97.

25 Dellon AL. Evaluation of sensibility and re-education of sensation in the hand. Baltimore: John D. Lucas Printing Co, 1988.

${ }^{26}$ Pönnighaus IM, Boerrigter G. Are 18 doses of WHO/MDT sufficient for multibacillary leprosy; results of a trial in Malawi. Int $J$ Lepr 1995; 63: 1-7.

\section{APPENDIX}

\section{Muscles tested in the voluntary muscle test}

Facial nerve: Orbicularis Oculi (only)-max score: 5, Ulnar nerve: First Dorsal Interosseus ('index finger out') and Abductor Digiti Minimi ('little finger out')-max score: 10, Median nerve: Abductor Pollicis Brevis and Opponens Pollicis ('thumb up')-max score: 10, Radial nerve: Extensor Carpi Ulnaris ('wrist up') and Extensor Digitorum Longus (finger extension)-max score: 10, Lateral Popliteal nerve: Extensor Hallucis Longus and Peroneus Longus \& Brevis ('lateral foot up')-max score: 10. If any particular muscle could not be tested (e.g. because of joint stiffness or previous surgery) or if test data were not available, the results for that nerve were excluded from the analysis. 
Sites tested in the touch sensibility test

Ulnar nerve: 3 points, on the pulp of dig. V,over the 5th metacarpophalangeal (MCP) joint and on the hypothemar eminence respectively-max score: 6 , Median nerve: 4 points, on the pulp of the thumb, over the 2nd MCP joint, the pulp of the index finger and the pulp of the middle finger respectively-max score: 8 , Posterior Tibial nerve: 10 points on the footsole: on the tip of each toe, over the 1st and 5th metatarsophalangeal joints, the inste p, the lateral border and the heel-max score: 20. If there was an ulcer on the test site a score of 0 was given for that site. Missing date were handled as for the VMT results. 